\title{
AMINATED WOOD SANDING DUST AS FILLER FOR RECYCLED POLYPROPYLENE-BASED COMPOSITE
}

\author{
GALIA SHULGA, BRIGITA NEIBERTE, ANRIJS VEROVKINS, \\ SANITA VITOLINA, JEVGENIJS JAUNSLAVIETIS, SANDRA LIVCHA and \\ TALRITS BETKERS
}

\author{
Latvian State Institute of Wood Chemistry, 27 Dzerbenes Str., LV-1006, Riga, Latvia \\ $\square$ Corresponding author: G. Shulga, galshulga@inbox.lv
}

Dedicated to the $70^{\text {th }}$ anniversary of the Department of Pulp and Paper, "Cristofor Simionescu” Faculty of Chemical Engineering and Environmental Protection,

"Gheorghe Asachi" Technical University of Iasi

\begin{abstract}
The aim of this work was to functionalise birch wood sanding dust, a waste from plywood production, for obtaining recycled polypropylene-based wood-polymer composites (WPCs). The functionalisation of the lignocellulosic waste was carried out through a two-step procedure, namely, by its alkaline pretreatment, followed by amination. The alkaline pretreatment increased the amount of weak acid functional groups, decreased the content of hemicelluloses and enhanced the relative content of cellulose in the lignocellulosic matrix. The amination of the alkaline treated dust was performed with diethylepoxypropylamine. This functionalisation allowed introducing tertiary amino groups in the matrix, the amount of which, in terms of nitrogen content, was $1.6 \%$ and $3.4 \%$. The WPC samples were prepared from recycled polypropylene and the aminated dust microparticles - by extrusion and moulding. The complex functionalisation of the birch sanding dust favoured the gain in the mechanical and hydrophobic properties of the WPC samples. Despite the positive effect of the functionalisation on the mechanical properties, the enhanced content of nitrogen in the dust particles deteriorated the hydrophobicity of the WPC samples due to the excess amount of hydrophilic amine groups in the lignocellulosic matrix.
\end{abstract}

Keywords: amination, functionalisation, recycled polypropylene, wood sanding dust, wood-polymer composite

\section{INTRODUCTION}

The strategy of the EU based on the bioeconomy and the circular economy principles focuses on rational and effective utilization of wood by-products and polymer wastes. In Latvia, forestry and wood processing are among the most developed economy areas, which form a lot of wood residues and by-products. The current usage of wood residues and by-products as a fuel is not rational in terms of both bioeconomy and the environment. Latvia, as well as other EU countries, also faces the problem of synthetic polymer wastes generated by plastic packaging and construction. The landfill and burning of these wastes are serious environmental problems. During burning and landfilling, toxic and carcinogenic substances, including carbon dioxide, are emitted into the environment and lead to climate changes. Reducing the concentration of atmospheric carbon dioxide is a fundamental challenge for the $21^{\text {st }}$ century. The other important problem is marine litter with polymeric wastes. It affects the world's oceans and seas, harming wild life, fisheries and tourism. The EU Directive 2018/852 sets out ambitious targets based on recycling and recovery of polymer wastes, preventing their leakage into the environment, as well as accelerating their usage efficiency. ${ }^{1}$

To minimize the negative effect on the environment and to rationally utilize wood biomass residues and polymer wastes, their joint usage for obtaining wood-polymer composite materials (WPCs) has promising prospects for both circular economy and the environment. WPCs are a young generation of semibiocomposites $^{2,3}$ with rapidly growing usage ${ }^{4}$ and could support the uptake of recycled plastics. The advantages of WPCs are known, namely, their low cost, biodegradability, light mass, 
enhanced filling degree etc. Due to their low cost and good performance, WPCs based on virgin polyolefin find wide application for making decking (about 67\%), composite materials for the auto industry $(23 \%)$ and domestic and technical needs $(10 \%)$. At the same time, the studies of WPCs based on recycled polymers, including thermoplastics, are limited, ${ }^{5-7}$ although recycled polymer-based composites could find their own application in the manufacture of various consumer goods.

It is well known that the main problem for WPCs is the low compatibility between a polymer matrix and a lignocellulosic filler. For the solution of the problem, two approaches are used, namely, functionalisation of lignocellulosic fibres and usage of functional additives, such as compatibilizers, coupling agents, adhesion enhancers, which are able to increase the compatibility between the filler and the matrix by lowering the free surface energy at the interface due to the formation of the interfacial structured layers. Attempts have been made for the development of compatibilizers based on lignin. ${ }^{8}$ It is known that the purposeful modification of lignin by oxidation, ${ }^{9}$ complexation with metal ions, ${ }^{10}$ esterification, ${ }^{11}$ alkylation, ${ }^{12}$ blending with synthetic polymers ${ }^{13}$ etc. can purposefully change both its structure and properties. Unfortunately, only a few lignin valorization products, mainly etherified lignin, meet the requirements of an interfacial adhesion enhancer for WPCs. ${ }^{14}$

There are various chemical methods for functionalization of lignocellulosic fibres as a filler (mercerisation, acetylation, benzylation, graft copolymerisation, treatment with acids, peroxide, various anhydrides, permanganate, silane etc.), which are aimed at increasing the physicochemical interaction between a polymer matrix and a lignocellulosic filler in WPC. ${ }^{15-20}$

Alkaline treatment is one of the most commonly used chemical treatments of lignocellulosic fibres for improving their properties as filler. During alkali treatment, the rupture of hydrogen bonding occurs in the fibre network structure. This increases the content of amorphous cellulose and the surface roughness of the fibres, as well as causes the disintegration of fibre bundles and the reduction of their sizes. Beside this, additionally, oils and wax are removed from the cell wall. ${ }^{17,21}$ In such a manner, the alkali treatment increases the availability of lignocellulose for interaction with chemical modifiers for their functionalisation. As a rule, enhanced concentrations of alkali solution at high temperatures and prolonged time are used during the alkaline treatment of lignocellulose. On the other hand, scarce information is available on the effect of low alkali concentrations and temperatures less than $100{ }^{\circ} \mathrm{C}$ on the properties of lignocellulosic fibres used as filler in WPCs.

Taking into account the fact that a recycled polymer has oxygen-containing groups, such as hydroxyl and carboxyl groups, in its composition, lignocellulose as filler should contain functionalities that will be able to interact with these groups during the processing of the composite materials. That is why, the amination of the lignocellulosic matrix of birch sanding dust was proposed for further functionalisation. It is known that the amination of lignin and lignocellulose has multipurpose application, for example, for obtaining sorbents for bile acids and cholesterol, ${ }^{22}$ reactive additives for polyurethane and epoxy resins ${ }^{23}$ ion exchanger materials for wastewater treatment ${ }^{24}$ etc.

The aim of this study was to improve interface adhesion in a wood-polymer composite by the complex functionalisation of wood sanding dust, comprising its alkaline pretreatment, followed by its amination with epoxy amine, and to characterise the properties of the obtained composite samples.

\section{EXPERIMENTAL}

\section{Materials}

Birch wood sanding dust, a waste from the mechanical treatment of plywood, was supplied by a Latvian company. The dust was characterized in terms of elemental analysis (Elementar Analysensysteme $\mathrm{GmbH}$, Germany) and wood polymers composition according to Klason and Kürschner's chemical procedures for lignin (TAPPI 2002-2003) ${ }^{25}$ and cellulose (TAPPI 1999), ${ }^{26}$ respectively, as well as hemicelluloses (TAPPI 1997). ${ }^{27}$ The found elemental composition of the wood residue was the following: $46.83 \% \mathrm{C}, 6.88 \% \mathrm{H}, 45.9 \% \mathrm{O}, 0.28 \% \mathrm{~N}, 0.11 \% \mathrm{~S}$. The content of cellulose, lignin, hemicelluloses, extractives and ash in the aspen wood was $47.74 \%, 20.32 \%$, $25.94 \%, 5.58 \%$ and $0.42 \%$, respectively. An optical image of the birch sanding dust is given in Figure 1.

The alkaline pretreatment was carried out by using a 5-L three-neck flask, equipped with a return condenser, a thermometer and a stirrer under the following conditions: a $\mathrm{NaOH}$ concentration of 0.05 $0.5 \mathrm{~g} / \mathrm{dL}$, temperature of $40-90^{\circ} \mathrm{C}$ and duration of $1 \mathrm{~h}$ at a hydromodulus (dust/water mass ratio) of $1 / 20$. The mass losses of the treated wood dust were used for calculating the amounts of the extracted water-soluble 
products formed as a result of the alkaline pretreatment.

The amination of the activated birch sanding particles was carried out with diethylepoxypropylamine (DEEPA), which was synthesised from diethylamine and epichlorohydrine, according to the procedure described by Zakis and Neiberte. ${ }^{28}$ For this purpose, $2 \mathrm{~mL}$ of water was added to diethylamine $(71 \mathrm{~mL})$ and epichlorohydrine $(54 \mathrm{~mL})$ to initiate the reaction. The mixture was stirred for 5$6 \mathrm{~h}$ at a temperature of $28-30{ }^{\circ} \mathrm{C}$ to form diethylaminooxy-propoxy-chloride. In the second stage, sodium hydroxide $(32.5 \mathrm{~g})$ and water $(53 \mathrm{~mL})$ were added to the obtained reagent. For amination, the treated dust was heated with DEEPA at the mass ratio of dust/DEEPA/distilled water of 1/0.5-1.5/15 for $1 \mathrm{~h}$ at $98{ }^{\circ} \mathrm{C}$ under constant stirring. After that, the obtained product was cooled and diluted with an equal volume of distilled water. Then, the functionalized dust particles were filtered, washed with a dilute solution of acetic acid to neutral medium. The aminated dust samples were dried at $60{ }^{\circ} \mathrm{C}$ for $48 \mathrm{~h}$ and the fixed nitrogen (N) content therein was analysed. The introduced nitrogen content in the dust particles was $1.6 \%\left(\mathrm{~N}_{\min }\right)$ to $3.4 \%\left(\mathrm{~N}_{\max }\right)$, not counting the content of nitrogen in the initial dust $(0.28 \% \mathrm{~N})$. The interaction of the phenolic hydroxyl groups of lignin and the hydroxyl groups of cellulose and hemicelluloses, at the lignocellulosic surface, with the aqueous solution of DEEPA resulted in the formation of lignocellulosic amino derivatives containing 2-hydroxy-3diethylamine-propoxy groups. ${ }^{21}$

Recycled polypropylene (rPP) in a powder form was used as a thermoplastic polymer matrix. It had a density of $0.9 \mathrm{t} \mathrm{m}^{-3}$ and a melt flow index of 5.2/10 min $\left(230{ }^{\circ} \mathrm{C}, 2.16 \mathrm{~kg}\right)$.

The WPC samples were prepared from rPP and the dust microparticles less than $100 \mu \mathrm{m}$, previously mixing them in an electrical mechanical grinder. A twin screw extruder and a moulding machine (HAAKE MiniLab II with MiniJet II, Thermo Scientific "HAKKE"), at a temperature of $175^{\circ} \mathrm{C}$, were used for the preparation of the composite samples. The rotational speed of the extruder screw was $130 \mathrm{~min}^{-1}$, while the injection moulding pressure was $60-70 \mathrm{MPa}$.
The microparticles' content in the composites was $30 \%$.

\section{Methods}

Milling

For obtaining a fraction less than $100 \mu \mathrm{m}$, both the initial and aminated birch sanding dust were milled and sieved. Milling was carried out with a planetary ball mill (Retsch, Germany) at $300 \mathrm{~min}^{-1}$ during $15 \mathrm{~min}$. The fractionation was performed by using Pulverizette 0 (Fritsch, Germany) during $30 \mathrm{~min}$.

\section{Potentiometric and conductometric titration}

The conductometric titration curves of the water suspensions of initial and alkaline treated dust particles were obtained using an InoLab level 3 Multiparameter Meter (WTW, Germany) under constant stirring at 25 ${ }^{\circ} \mathrm{C}$. $0.1 \mathrm{~mol} / \mathrm{dm}^{3} \mathrm{HCl}$ solution was used for the adjustment of $\mathrm{pH}$ values.

\section{Wetting properties of WPC samples}

To study the surface properties, WPC samples with dimensions of $60 \times 10 \times 1 \mathrm{~mm}$ were prepared. Before testing, the samples were conditioned at $60{ }^{\circ} \mathrm{C}$ and $5 \%$ humidity for $24 \mathrm{~h}$ and then stored for $1 \mathrm{~h}$ at room temperature in a desiccator with phosphorus pentoxide. The advancing and receding contact angles of the WPC samples were measured with a Kruss K100M tensiometer (Germany), using the Wilhelmy method.

The water sorption and swelling of the composite samples were determined after their full immersion in distilled water for 16 days at $20{ }^{\circ} \mathrm{C}$. Three replicates were made for each testing.

\section{Mechanical tests}

Mechanical properties were determined with a universal Zwick machine (Zwick/Roell, Germany), with a load capacity of $0.5 \mathrm{kN}$, at a rate of $50 \mathrm{~mm} / \mathrm{min}$ and $2 \mathrm{~mm} / \mathrm{min}$ for tensile and bending tests, respectively, according to ASTM D638 ${ }^{15}$ (ASTM 2007) and EN ISO $178^{16}$ (EN ISO 2003) with the help of the software program TestXpert. Before testing, the samples were conditioned at $60{ }^{\circ} \mathrm{C}$ during $24 \mathrm{~h}$ and then placed in a desiccator with phosphorus pentoxide. Five replicates were made for each mechanical testing, and the standard deviation for each index was found.

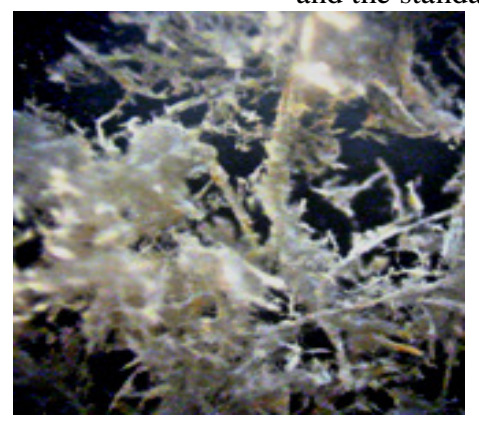

Figure 1: Optical image of the birch sanding dust (x40 magnification) 


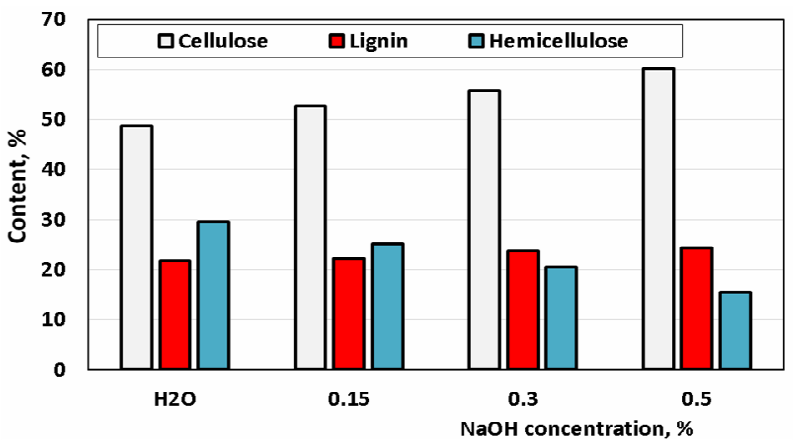

Figure 2: Changes in chemical composition of birch wood sanding dust after alkaline treatment at $60{ }^{\circ} \mathrm{C}$

\section{FT-IR spectroscopy}

The FT-IR spectra were recorded on a spectrometer (Perkin-Elmer Spectrum One, USA). For this purpose, small shreds from the WPC samples were obtained by rubbing them on a grate. Then, they were carefully ground in the mortar and mixed with $\mathrm{KBr}$ powder. For the preparation of the samples, the tablet compression method was used.

\section{Transmission electron microscopy (TEM)}

The shape of the dust particles was measured by transmission electron microscopy (Leo 912 AB Omega microscope, Carl Zeiss, Germany).

\section{Scanning electron microscopy (SEM)}

The morphology of the obtained WPC samples was examined using a scanning electron microscope (Tesla, Czech Republic).

\section{RESULTS AND DISCUSSION}

\section{Functionalization of birch wood dust particles}

The study of the effect of the alkali treatment of the birch sanding dust at a hydromodulus of $1 / 20$ (dust/alkaline solution) and a temperature of $60{ }^{\circ} \mathrm{C}$ for $1 \mathrm{~h}$ on the amount of the released watersoluble products (extractives, low molecular hemicelluloses, lignin and lignin-carbohydrate complexes), formed as a result of the hydrolysis of ester bonds in the lignocellulosic matrix, shows that, with applying from $0.15 \%$ to $0.50 \% \mathrm{NaOH}$, their content in the alkaline solution increases from 5.5 to 16.3 times (Fig. 2), but the yield of the treated dust particles decreases from $92.8 \%$ to $78.2 \%$ in comparison with the case of dust hydrolysis in distilled water. It is seen that, with increasing the alkali concentration, the relative content of cellulose increases, but the hemicelluloses content decreases, while the amount of lignin in the treated wood dust is not significantly changed.

With increasing the temperature from $40{ }^{\circ} \mathrm{C}$ to $90{ }^{\circ} \mathrm{C}$ and the concentration of the alkaline solution from $0.15 \%$ to $0.50 \%$, the amount of the water-soluble products remarkably grows, and the loss of the dust mass achieves $24.6 \%$ (Fig. 3) for a $0.50 \% \mathrm{NaOH}$ solution and the applied temperature of $90{ }^{\circ} \mathrm{C}$, indicating the essential hydrolytic destruction of the lignocellulosic surface of the birch sanding dust particles. As the obtained results showed, the increase of reduced viscosity from 0.005 to $0.030 \mathrm{dL} / \mathrm{g}$ and the decrease of surface tension at the air-water interface from $54.5 \mathrm{mN} / \mathrm{m}$ to $52.5 \mathrm{mN} / \mathrm{m}$ of a $0.50 \% \mathrm{NaOH}$ alkaline solution, containing watersoluble hydrolysed products, at a growing temperature, confirmed that hemicelluloses were the main part of the released hydrolysed products. Monosugars in the alkaline solution were determined by high performance liquid chromatography (HPLC), using a SHIMADZU LC-20A chromatograph with a refraction index detector. The identifying chromatography analysis testified the presence of xylose, mannose, arabinose, rhamnose and glucose monomers in the alkaline solutions after the pretreatment of the birch sanding dust.

Table 1 shows the results of the chemical analysis of the dust particles treated at different temperature with the same alkali concentration solution, hydromodulus and time. It can be seen that the increase in the treatment temperature from $40{ }^{\circ} \mathrm{C}$ to $90{ }^{\circ} \mathrm{C}$ leads to an increase in the relative content of cellulose and lignin in the lignocellulosic matrix by $10.1-13.4 \%$ and 4.5 $5.3 \%$, respectively, but the hemicelluloses content in the treated dust particles decreases by $33-50 \%$ in comparison with the chemical composition of the initial dust. The increase of the $\mathrm{O} / \mathrm{C}$ value from 1.13 to 1.16 with the growth of the temperature indicates an enhanced amount of oxygen-containing functional groups in the lignocellulosic matrix treated at the highest temperature. 
The cleavage of the ester bonds in the lignocellulosic matrix leads to an increase in the content of weak acid groups. The conductometric curves (Fig. 4) testify the growth in the content of phenolic hydroxyl and carboxylic groups from $2.7 \%$ to $4.8 \%$ in the treated dust particles. Herewith, due to the formation of the additional negatively charged functional groups, the negative $Z$ potential values, characterising the charge of the dust particles, increased from $-9.7 \mathrm{mv}$ for the initial dust particles to -25.2 and $-34.1 \mathrm{mv}$ for the particles treated with a $0.50 \% \mathrm{NaOH}$ solution at $60{ }^{\circ} \mathrm{C}$ and $90{ }^{\circ} \mathrm{C}$, respectively.

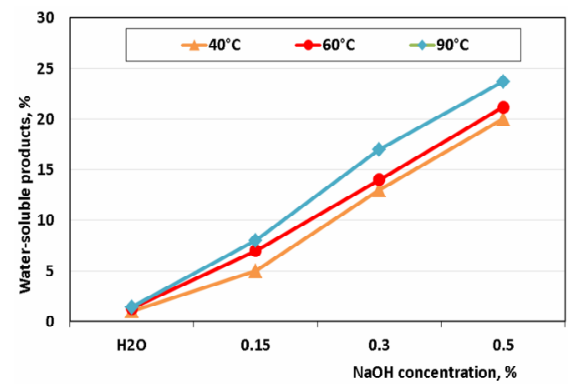

Figure 3: Dependence of the content of released watersoluble products in alkaline solution on applied $\mathrm{NaOH}$ concentration at different temperature
The performed fractional analysis of the particle size distribution within the fraction $<100$ $\mu \mathrm{m}$ showed that the fraction volume was mainly occupied by the microparticles with the size less than $70 \mu \mathrm{m}$ with a wide degree of dispersity. The study of the obtained hydrolysed microparticles by TEM revealed the prevalence of two types of microparticle shape, namely, oval, with an average diameter of 2-3 $\mu \mathrm{m}$, and an extended one, with the length of 4-6 $\mu \mathrm{m}$ and the width of 0.5-1.5 $\mu \mathrm{m}$ (Fig. 5), respectively. The low aspect ratio between the width and length of the obtained microparticles indicates their short fibre nature.

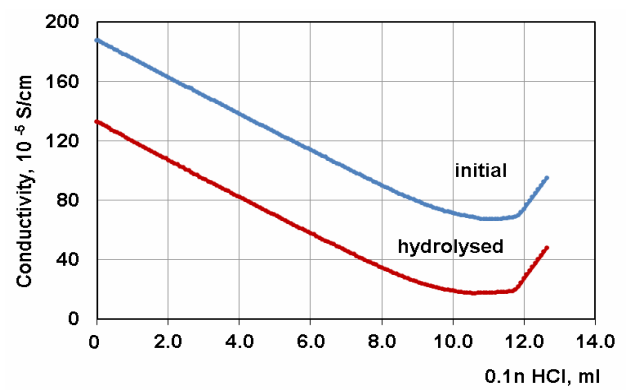

Figure 4: Conductometric titration curves of water suspensions of initial and alkaline treated dust particles with a $0.50 \% \mathrm{NaOH}$ solution at $60{ }^{\circ} \mathrm{C}$

Table 1

Composition, yield and oxidation degree of birch sanding dust treated with $0.50 \% \mathrm{NaOH}$ solution at different temperature $(1 \mathrm{~h}, 1 / 20)$

\begin{tabular}{cccccc}
\hline $\begin{array}{c}\text { Temperature } \\
\left({ }^{\circ} \mathrm{C}\right)\end{array}$ & $\begin{array}{c}\text { Cel. } \\
(\%)\end{array}$ & $\begin{array}{c}\text { Lig., } \\
(\%)\end{array}$ & $\begin{array}{c}\mathrm{HC} \\
(\%)\end{array}$ & $\begin{array}{c}\text { Yield } \\
(\%)\end{array}$ & $\mathrm{O} / \mathrm{C}$ \\
\hline 40 & 57.8 & 24.8 & 17.4 & 84.3 & 1.13 \\
60 & 60.1 & 24.4 & 15.5 & 78.8 & 1.15 \\
90 & 61.3 & 25.7 & 13.0 & 74.4 & 1.16 \\
\hline
\end{tabular}
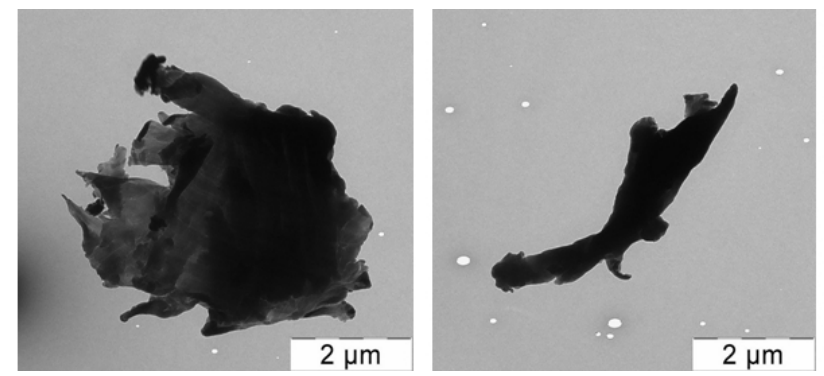

Figure 5: TEM micrographs of milled alkaline treated dust particles

Since the alkaline pretreatment at $90{ }^{\circ} \mathrm{C}$ led to pronounced destruction of the lignocellulosic matrix (Table 1) that could deteriorate its reinforcement function as a composite filler, for the pretreatment of the birch dust, we used a moderate temperature of $60{ }^{\circ} \mathrm{C}$ and a $0.50 \%$ concentration of the alkaline solution. 


\section{GALIA SHULGA et al.}

The interaction of the hydroxyl groups of lignin and cellulose, on the alkaline treated lignocellulosic surface (LC) of the birch sanding dust, in the aqueous solution of DEEPA at enhanced temperature, resulted in the formation of the aminated lignocelluloses products, containing 2-hydroxy-3-diethylamine-propoxy groups, according to the scheme given in Figure 6.

The performed DTA and DTG analyses showed that the thermostability of the aminated dust microparticles did not essentially differ from that of the alkali pretreated ones, namely, their mass losses at the processing temperature (175 ${ }^{\circ} \mathrm{C}$ ) varied from 8.1 to $9.2 \%$, and were mainly related to the content of residual moisture.

\section{Properties of the composites}

The mechanical properties of the WPC samples containing 30 mass $\%$ of initial and functionalised birch dust microparticles, with various content of nitrogen, are represented in Figure 7 (a, b, c).

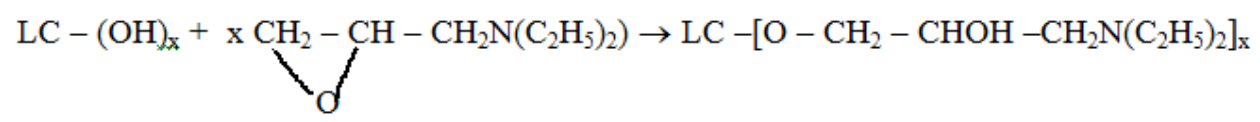

Figure 6: Scheme of amination of lignocellulose with epoxy amine

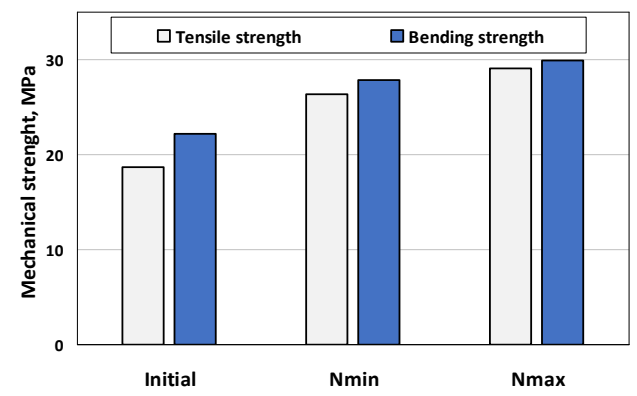

a)
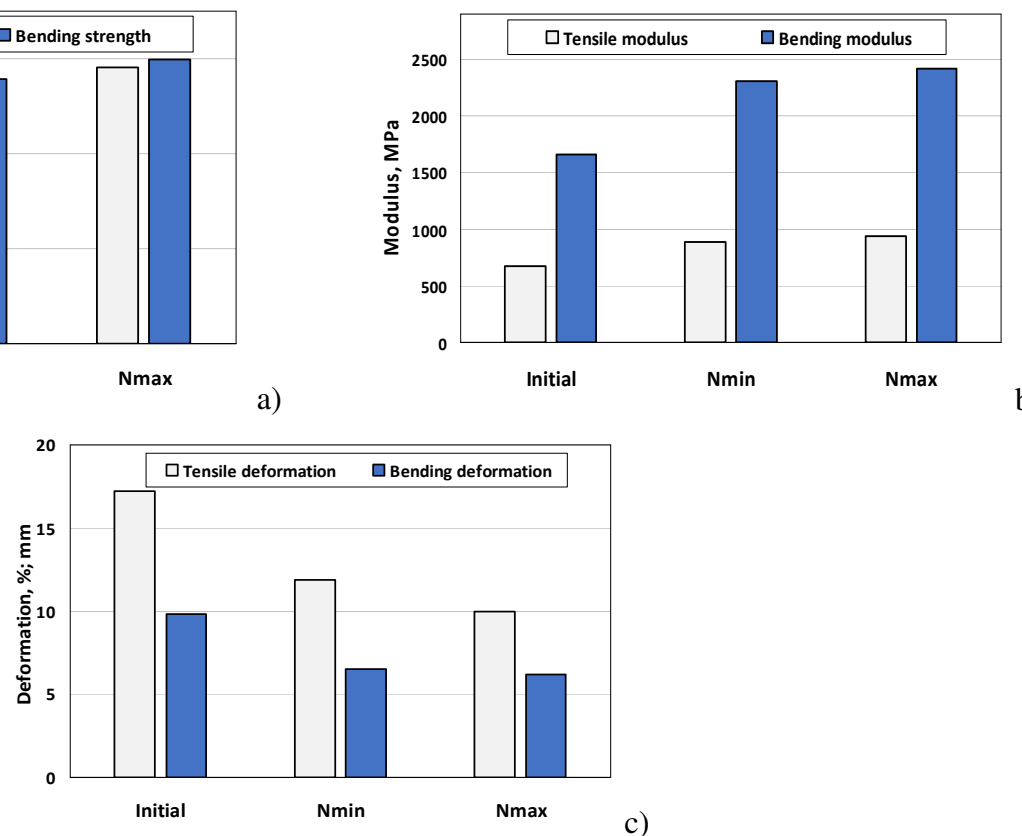

c)

Figure 7: Tensile and bending strength (a), tensile and bending modulus (b), deformation of the composite samples: elongation $(\%)$ and deflection $(\mathrm{mm})$

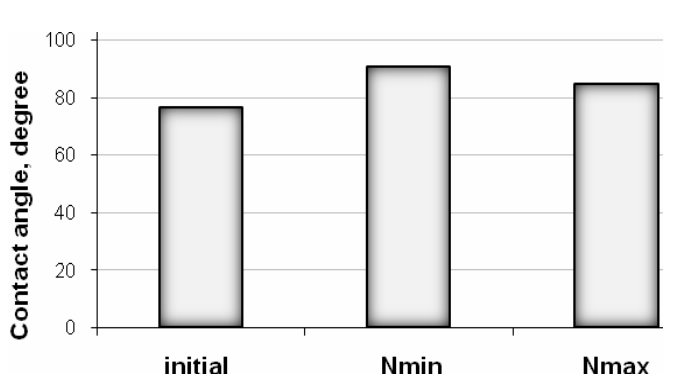

Figure 8: Contact angles of composite samples filled with initial and aminated dust particles (30\% filling on dry mass)

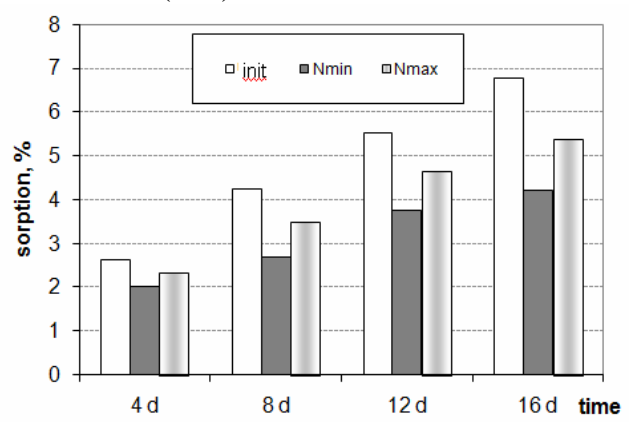

Figure 9: Water sorption of composite samples filled with initial and aminated dust particles with different nitrogen content 
It is seen that the complex functionalisation of the birch sanding dust favours the gain in the mechanical properties of the WPC samples. The tensile strength and modulus of elasticity of the WPC samples filled with aminated dust particles vary from 26.3 $\mathrm{MPa}$ to $29.1 \mathrm{MPa}$ and from 890 $\mathrm{MPa}$ and $935 \mathrm{MPa}$, respectively, but the bending strength and its modulus change from $27.8 \mathrm{MPa}$ to $29.9 \mathrm{MPa}$ and from $2310 \mathrm{MPa}$ to $2420 \mathrm{MPa}$, respectively, with increasing the content of fixed nitrogen. As compared with the case of the sample filled with initial sanding dust, the tensile and bending strength at break of the composite samples filled with aminated lignocellulosic particles increased by $41-56 \%$ and $25-35 \%$, respectively, but the tensile and bending modulus of rupture enhanced by $33-40 \%$ and $39-46 \%$, respectively. Simultaneously, the deformability of the obtained composites essentially decreases, which indicates an enhancement in their stiffness. The obtained results demonstrate that the interface adhesion between the recycled polypropylene and the aminated dust particles is increased due to the presence of the amino groups on the lignocellulosic surface, which are able to interact with the hydroxyl and carboxyl groups of the recycled polymer with the formation of the joint physicochemical bonds network. According to Figure 7, the composite samples filled with dust particles, containing the maximal and minimal amounts of nitrogen, differ in mechanical properties. The filler with a higher content of amine groups is able to provide better mechanical properties, both tensile and bending ones, to the composite material.

It is known that wettability is one of the most important characteristics of WPCs for their exploitation, determining their end-use applications. It fully depends on the adhesion quality between the polymer and the lignocellulosic filler. The larger the wettability of a wood-polymer composite, the smaller the interfacial adhesion in it. According to Figure 8, the WPC samples filled with the aminated dust particles are characterized by an increase in the contact angle values from $76.5^{\circ}$ for the composite with the initial dust to $90.6^{\circ}$ and $84.5^{\circ}$ for the composite samples containing the dust particles with the minimal $\left(\mathrm{N}_{\min }\right)$ and maximal $\left(\mathrm{N}_{\max }\right)$ content of nitrogen, respectively, at the same filling degree.

The water sorption was measured for $4,8,12$ and 16 days. For this purpose, the samples were totally immersed in distilled water at room temperature. As Figure 9 shows, the water sorption values of the composites with the aminated dust particles are essentially lower than those for the sample with the initial dust. The difference in water sorption between the samples filled with the initial and aminated dust makes $1.2-2.6 \%$ at the end of the measurement, depending on the fixed nitrogen content.

The obtained results show an improvement in the compatibility between the filler and recycled polypropylene in the composite material, which could be explained by the physicochemical interaction between the oxygen-containing groups of the recycled polymer and the tertiary amine groups of the functionalised dust microparticles at the interface. Despite the positive effect of the presence of the amine groups in the filler on the mechanical properties, their enhanced content in the aminated birch dust, simultaneously, decreases the hydrophobicity of the WPC sample. The obtained results (Figs. 8, 9) testify that the composite sample filled with particles containing $3.4 \%$ fixed nitrogen is characterised by a lower contact angle and a higher adsorbed water amount, in comparison with the sample containing microparticles with $1.6 \%$ nitrogen.

The obtained FTIR spectra (Fig. 10) show the difference in the amount of hydrophilic groups in the composite samples, containing various contents of amine groups. According to the differential spectrum (the difference in the absorption band intensities between the samples with $\mathrm{N}_{\min }$ and $\mathrm{N}_{\max }$ ), the samples filled with microparticles with the highest nitrogen content have enhanced absorption in the following areas: 3700-3300 $\mathrm{cm}^{-1}$ (hydroxyl groups), 3300-3000 $\mathrm{cm}^{-1}$ (O-H bonds), 1750-1300 $\mathrm{cm}^{-1}$ (carbonyl, carboxyl groups) and $1300-900 \mathrm{~cm}^{-1}$ (C-N, C-O and $\mathrm{O}-\mathrm{H}$ bonds). It can be assumed that the enhanced content of other lyophilic groups in the aminated dust particles with the maximal nitrogen content is a consequence of the side effects of the amination, as a result of the introduction of an increased concentration of the alkaline solution introduced together with DEEPA.

The conducted morphology study of the obtained composite samples confirms the increase of the interface adhesion between the aminated lignocellulosic filler and the recycled polypropylene. The comparison of the SEM images (Fig. 11) of the composite surfaces indicates a much greater homogeneity and the 
GALIA SHULGA et al.

lack of surface voids in the composite, containing $30 \%$ of aminated birch dust microparticles, in comparison with the sample filled with initial dust.

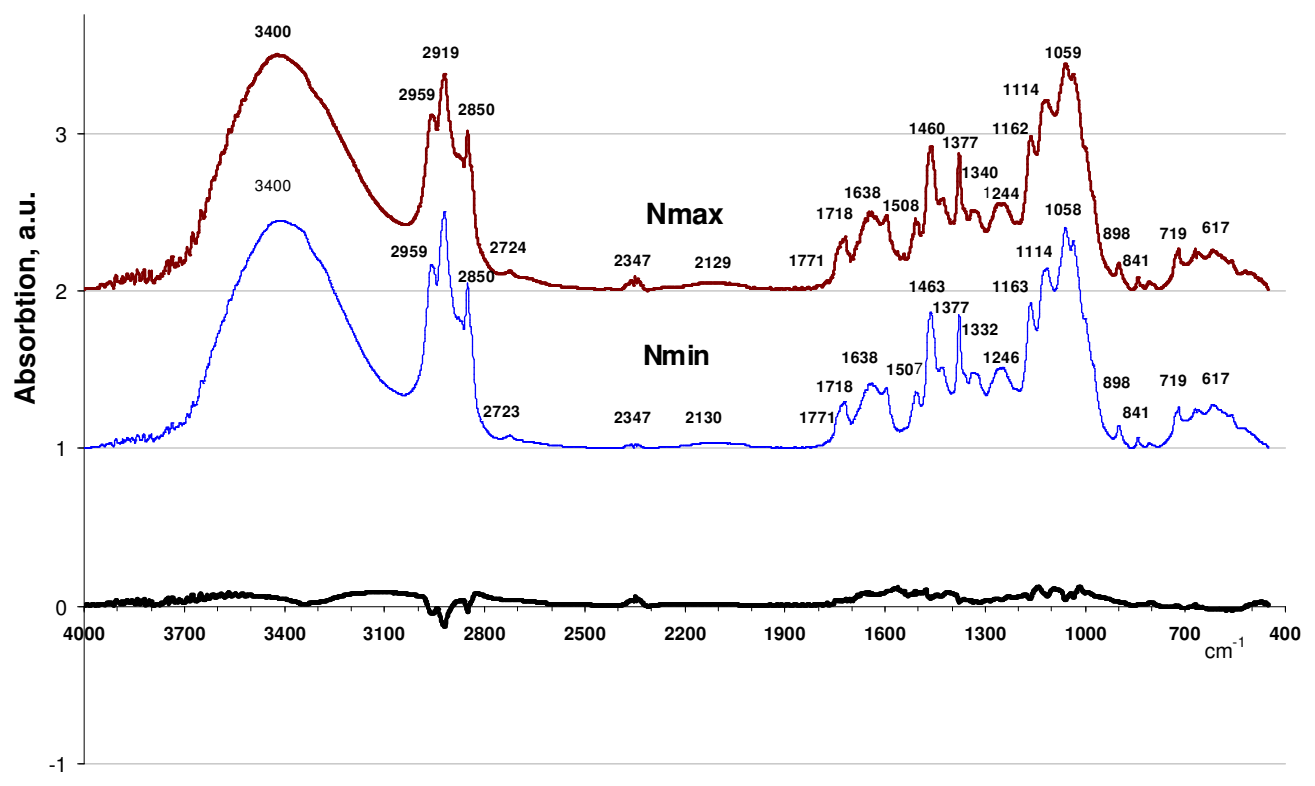

Figure 10: FTIR spectrum and FTIR differential spectra of composite samples filled with aminated dust particles with different nitrogen content
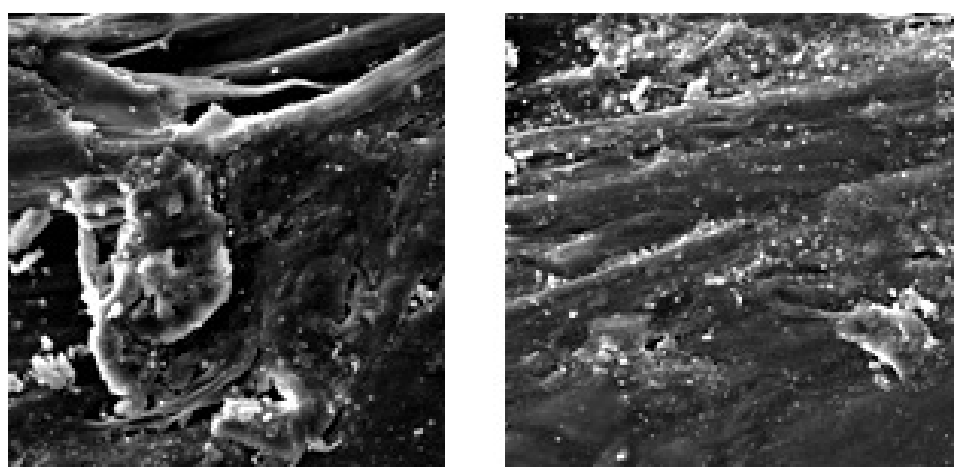

Figure 11: SEM images of composite samples filled with initial (on the left) and aminated dust particles (on the right), (x2000 magnification)

\section{CONCLUSION}

The functionalization of birch wood sanding dust, a waste from plywood production, was carried out by its amination with alkaline pretreatment. The optimal parameters of the alkaline pretreatment, such as sodium hydroxide concentration and temperature, for obtaining activated dust particles were found. The choice of the parameters was based on a compromise between the lignocellulosic surface destruction and its activation for further amination. The alkaline pretreatment increased the amount of weak acid functional groups, decreased the content of hemicelluloses and enhanced the relative content of cellulose in the lignocellulosic matrix. The amination with diethylepoxypropylamine introduced tertiary amino groups in the birch sanding dust, the amount of which in terms of nitrogen content was $1.6 \%$ and $3.4 \%$. The complex functionalization of the dust favoured the gain in the mechanical and hydrophobic properties of the WPC samples fabricated from recycled polypropylene and aminated dust microparticles. Despite the positive effect of amination on the mechanical properties, the enhanced content of nitrogen of $3.4 \%$ in the 
functionalized dust particles decreased the contact angle value and increased the water sorption of the WPC sample, in comparison with the sample filled with particles containing less nitrogen content.

ACKNOWLEDGEMENTS: This work received financial support from the Forest Sector Competence Centre of Latvia (P2 project "Study of the application potentialities of woodworking by-products", No. KC/2.1.2.1.1/10/01/003).

\section{REFERENCES}

Directive (EU) 2018/852 of the European Parliament and of the Council of 30.05 .2018 on packaging and packaging waste, https:// eurlex.europa.eu/legal-

content/EN/TXT/?uri=uriserv:OJ.L_.2018.150.01.0141 01.ENG\&toc $=$ OJ:L:2018:150:TOC

2 M. J. John and R. D. Anandjiwala, Polym. Compos., $\quad 29, \quad 187 \quad$ (2008), https://doi.org/10.1002/pc.20461

3 S. Nie, X. Liu, K. Wu, G. Dai and Y. Hu, J. Therm. Anal. Calorim., 111, $425 \quad$ (2013), https://doi.org/10.1007/s10973-012-2422-3

4 M. Carus, A. Eder, L. Dammer, H. Korte, L. Scholz et al., in "Wood-Plastic Composites (WPC) and Natural Fibre Composites (NFC): European and Global Markets 2012 and Future Trends in Automotive and Construction", Nova-Institut GmbH, Germany, 2015, 16

https://compositesuk.co.uk/system/files/documents/WP C-NFC-Market-Study-Short-Verson\%202015.pdf

S. K. Najafi, Waste Manage., 33, 1898 (2013), https://doi.org/10.1016/j.wasman.2013.05.017

6 G. Shulga, B. Neiberte, A. Verovkins, S. Vitolina, J. Jaunslavietis et al., Materials Science (Medžiagotyra), $\quad$ 22, $370 \quad$ (2016), http://dx.doi.org/10.5755/j01.ms.22.3.8752

I. Turku, T. Kärki and A. Puurtinen, Heliyon, 4, e00559

(2018), https://doi.org/10.1016/j.heliyon.2018.e00559

8 N. Mariotti, T. Stevanovic, D. Rodrigue and X.-M. Wang, in "Lignin: Structural Analysis, Applications in Biomaterials and Ecological Significance", edited by F. Lu, Nova Science Publishers, New York, 2014, pp. 238-308

9 G. Shulga, V. Shakels, O. Aniskevicha, T. Bikova and A. Treimanis, Cellulose Chem. Technol., 40, 383 (2006), http://www.cellulosechemtechnol.ro

10 R. Garcia-Valls and T. A. Hatton, Chem. Eng. J., 94, 99 (2003), https://doi.org/10.1016/S13858947(03)00007-X

11 W. Thielmans and R. P. Wool, Compos. Part A, 35, 327

(2004).

https://doi.org/10.1016/j.compositesa.2003.09.011
12 I. Kühnel, J. Podschun, B. Saake and R. Lehnen, Holzforschung, $\quad 69, \quad 531 \quad$ (2014), https://doi.org/10.1515/hf-2014-0068

13 G. Shulga, P. Solodovniks and V. Shakels, Cellulose Chem. Technol., 39, 563 (2005), http://www.cellulosechemtechnol.ro

14 K. Kun and B. Pukanszky, Eur. Polym. J., 93, 618 (2017), https://doi.org/10.1016/j.eurpolymj.2017.04.035

15 M. Farsi, Asian J. Chem., 24, 2775 (2012), www.asianjournalofchemistry.co.in

16 M. Ho, H. Wang, J.-H. Lee, C. Ho, K. Lau et al., Compos. Part B Eng., 43, 3549 (2012), https://doi.org/10.1016/j.compositesb.2011.10.001

17 N. Cordeiro, M. Ornelas, A. Ashori, S. Sheshmaniand and H. Norouzi, Carbohyd. Polym., 87, 2367

(2012), https://doi.org/10.1016/j.carbpol.2011.11.001

18 X. Li, L. G. Tabiland and S. Panigrahi, J. Polym. Environ., $\quad \mathbf{1 5}, \quad 25 \quad$ (2007), https://doi.org/10.1007/s10924-006-0042-3

19 M. M. Kabir, H. Wang, K. T. Lauand and F. Cardona, Compos. Part B Eng., 43, 2883 (2012), https://doi.org/10.1016/j.compositesb.2012.04.053

${ }^{20}$ G. Shulga, J. Jaunslavietis, J. Ozolins, B. Neiberte, A. Verovkins et al., in Procs. AIP Conference - Times of Polymers \& Composites. From Aerospace to Nanotechnology, Naples, June 19-23, 1736, 020111 (2016), https://doi.org/10.1063/1.4949686

21 G. Rajesh and A. V.R. Prasad, IJAMMC, 3, 528 (2013), https://doi.org/10.1016/j.mspro.2014.07.425

22 G. Zakis, B. Neiberte and A. Verovkins, in Procs. $8^{\text {th }}$ European Workshop on Lignocellulosics and Pulp, Riga, August 22-25, 2004, pp. 451-455

${ }^{23}$ H. Pan, G. Sun and T. Zhao, Int. J. Biol. Macromol., $\quad 59, \quad 221 \quad$ (2013), http://dx.doi.org/10.1016/j.ijbiomac.2013.04.049

24 A. Keränen, T. Leiviskä, I. Zinicovscaia, M. V. Frontasyeva, O. Hormi et al., Environ. Technol., 37, 1390 https://doi.org/10.1080/09593330.2015.1116611 (2016),

${ }_{25}$ TAPPI 2002-2003, T 222 om-02, in: “TAPPI Test Methods", TAPPI Press, Atlanta, GA, USA, https://standards.globalspec.com/std/10402544/tappi-t222

26 TAPPI 1999, T 203 cm-99, in: "TAPPI Test Methods", TAPPI Press, Atlanta, GA, USA, https://research.cnr.ncsu.edu/wpsanalytical/documents/ T203.PDF

27 TAPPI 1997, T 264 om-97, in: "TAPPI Test Methods", TAPPI Press, Atlanta, GA, USA, https://www.tappi.org

${ }_{28}$ G. Zakis and B. Neiberte, Latv. J. Chem., 4, 89 , (2000), https://www.researchgate.net/journal/08688249_Latvian_Journal_of_Chemistry 